\title{
Synthesis, structure and Hirshfeld surface analysis, vibrational and DFT investigation of (4-pyridine carboxylic acid) tetrachlorocuprate (II) monohydrate
}

\author{
KHAOULA AZOUZI*, BESMA HAMDI, RIDHA ZOUARI and ABDELHAMID BEN SALAH \\ Laboratory of Materials Science and Environment, Faculty of Sciences of Sfax, University of Sfax, Sfax, Tunisia
}

MS received 26 April 2016; accepted 2 March 2017

\begin{abstract}
The new organic-inorganic hybrid compound $\left[\mathrm{C}_{6} \mathrm{H}_{6} \mathrm{NO}_{2}\right]_{2} \mathrm{CuCl}_{4} \cdot \mathrm{H}_{2} \mathrm{O}$ has been grown from an aqueous mixture by the solvent evaporation method. X-ray diffraction, Hirshfeld surface analysis, FT-IR and FT-Raman spectroscopy were applied to characterize the composition and crystal structure of the complex. It is crystallized in a triclinic system ( $P \overline{1}$ space group). The structure of this compound might be described as layered with two parallel anionic and cationic layers. The first layer is composed of isolated square planar $\left[\mathrm{CuCl}_{4}\right]^{2-}$ and the second layer of $\left[\mathrm{C}_{6} \mathrm{H}_{6} \mathrm{NO}_{2}\right]^{2+}$. The water molecule is placed between the layers formed by organic cations along the $b$ axis. Network hydrogen-bonding and $\pi-\pi$ interactions lead to the formation of a three-dimensional architecture. Hirshfeld surface analysis for visually analysing intermolecular interactions in crystal structures employing molecular surface contours and 2D fingerprint plots has been used to scrutinize molecular shapes. The vibration properties of this structure were studied by IR spectroscopy and Raman scattering. Vibration spectra were also calculated theoretically by means of Gaussian 03 package of programs within the density functional theory (DFT) framework using the B3LYP/LanL2DZ level of theory. To sum up, good consistency is found between the calculated results on one hand and the IR and Raman spectra and experimental structure on the other. This study confirms the presence of the organic cations $\left[\mathrm{C}_{6} \mathrm{H}_{6} \mathrm{NO}_{2}\right]^{2+}$, the inorganic anions $\left[\mathrm{CuCl}_{4}\right]^{2-}$ and $\mathrm{H}_{2} \mathrm{O}$.
\end{abstract}

Keywords. Crystal structure; Hirshfeld surface; FT-IR; Raman; DFT/B3LYP/LanL2DZ.

\section{Introduction}

In recent years, layered hybrid organic-inorganic compounds based on metal halide units have attracted much attention due to their possibility to combine the properties of organic and inorganic materials at the molecular level [1]. In fact, organic compounds offer a number of useful properties, including structural diversity, mechanical plasticity and ease of processing [2]. Inorganic materials have a distinct set of advantages, including good electric mobility, tunable band gap property, magnetic property and thermal stability $[3,4]$. In these materials, the structural arrangement can be described as an alternation of inorganic sheets and layers of the organic molecules. The nature of the interface has been used to grossly divide these materials into two distinct classes. In class I, organic and inorganic compounds are embedded and only weak bonds (hydrogen, van der Waals or ionic bonds) give the cohesion to the whole structure. In class II materials, the two phases are linked together through strong chemical bonds (covalent or iono-covalent bonds). Much of the recent research has focused on the synthesis of crystalline organicinorganic halogenocuprates (II) due to the fact that they show a high variety of coordination numbers and geometries

\footnotetext{
*Author for correspondence (azouzi.khaoula@yahoo.fr)
}

(tetrahedral [5], trigonal bi-pyramidal [6] square pyramidal and octahedral [7]). This large structural variability of $\mathrm{Cu}$ (II) is due to the presence of an active Jahn-Teller effect in the $\mathrm{d}^{9}$ electronic system [8].

In this work, we focused our attention on the synthesis and characterization of a new hybrid material $\left[\mathrm{C}_{6} \mathrm{H}_{6} \mathrm{NO}_{2}\right] \mathrm{CuCl}_{4} \cdot \mathrm{H}_{2} \mathrm{O}$, which is crystallized in space group $P \overline{1}$. We have used X-ray diffraction measurements, which provided us with information about the complete crystal structure at room temperature. An investigation of close intermolecular interactions in this compound via Hirshfeld surface analysis is also reported. Besides, the geometric parameters and vibrational frequencies of (4-pyridine carboxylic acid) tetrachlorocuprate (II) monohydrate have been investigated by the DFT/B3LYP/LanL2DZ method. Moreover, the FT-IR and FT-Raman spectra have been recorded in the range of $400-4000$ and $50-4000 \mathrm{~cm}^{-1}$, respectively.

\section{Experimental}

\subsection{Synthesis of $\left[\mathrm{C}_{6} \mathrm{H}_{6} \mathrm{NO}_{2}\right] \mathrm{CuCl}_{4} \cdot \mathrm{H}_{2} \mathrm{O}$}

The (4-pyridine carboxylic acid) tetrachlorocuprate (II) monohydrate crystals were prepared by dissolving $\mathrm{CuCl}_{2} \cdot 6 \mathrm{H}_{2} \mathrm{O}$ in a minimum volume of water and $\left[\mathrm{C}_{6} \mathrm{H}_{6} \mathrm{NO}_{2}\right]$ in concentrated $\mathrm{HCl}$. After the solutions were mixed, it remained clear 
without any precipitate. The resulting aqueous solution was left to evaporate slowly at room temperature. After 2 weeks, high-quality yellow crystals appeared in the solution and became stable under normal conditions of temperature and humidity. The average value of density, $D=2.601 \mathrm{mg} \mathrm{m}^{-3}$, is in agreement with that calculated, $D=2.649 \mathrm{mg} \mathrm{m}^{-3}$.

\subsection{Crystal data and structure determination}

For the structural study we chose a crystal with the dimensions of $0.31 \times 0.28 \times 0.19 \mathrm{~mm}^{3}$. The single crystal was fixed on a Bruker APEXII CCD four-circle diffractometer; MoK $\alpha$ radiation ( $\lambda=0.71073 \AA$ ) was used in order to study its structural analysis. The crystal structure has been solved in the triclinic system, space group $P \overline{1}$ according to the automated search for space group available in WINGX [9]. The crystal structure has been solved using the classical method: interpretation of the three-dimensional Patterson function followed by successive difference Fourier maps after introducing anisotropic thermal factors for the non-hydrogen atoms and isotropic thermal factors for $\mathrm{H}$ atoms. The structure was solved and refined using SHELXS-97 and SHELXL-97 programs $[10,11]$ respectively, down to $R=0.04$ and $w \mathrm{R} 2=$ 0.10 . The structural graphics were created with ORTEP [12] and DIAMOND [13]. The crystallographic data and some details of the structural refinement are summarized in table 1. The atomic coordinates and equivalent isotropic and anisotropic thermal agitation factors are listed in tables 2 and 3 , respectively.

\subsection{Hirshfeld surfaces computational method}

The Hirshfeld surfaces and the associated 2D fingerprint plots were calculated using the Crystal Explorer [14] program, which accepts a structure input file in the CIF format. A Hirshfeld surface is the outer contour of the space which a molecule or an atom consumes in a crystalline environment. The normalized contact distance $d_{\text {norm }}$ based on both $d_{\mathrm{e}}$ (distance from the point to the nearest nucleus external to the surface) and $d_{\mathrm{i}}$ (distance to the nearest nucleus internal to the surface) and the van der Waals ( $\mathrm{vdW}$ ) radii of the atom, given by equation (1), enables identification of the regions of particular importance to intermolecular interactions [15]:

$$
d_{\text {norm }}=\frac{\left(d_{\mathrm{i}}-r_{\mathrm{i}}^{\mathrm{vdw}}\right)}{r_{\mathrm{i}}^{\mathrm{vdw}}}+\frac{\left(d_{\mathrm{e}}-r_{\mathrm{e}}^{\mathrm{vdw}}\right)}{r_{\mathrm{e}}} .
$$

The value of the $d_{\text {norm }}$ is negative or positive when intermolecular contacts are, respectively, shorter or longer than $\mathrm{vdW}$ separations. Because of the symmetry between $d_{\mathrm{e}}$ and $d_{\mathrm{i}}$ in the expression for $d_{\text {norm }}$, where two Hirshfeld surfaces

Table 1. Crystal data and structure refinement for $\left[\mathrm{C}_{6} \mathrm{H}_{6} \mathrm{NO}_{2}\right]_{2} \mathrm{CuCl}_{4} \cdot \mathrm{H}_{2} \mathrm{O}$.

\begin{tabular}{|c|c|}
\hline \multicolumn{2}{|c|}{ Crystal data } \\
\hline Empirical formula & {$\left[\mathrm{C}_{6} \mathrm{H}_{6} \mathrm{NO}_{2}\right] \mathrm{CuCl}_{4} \cdot \mathrm{H}_{2} \mathrm{O}$} \\
\hline Formula weight & 489.62 \\
\hline Crystal system & Triclinic \\
\hline Space group & $P \overline{1}$ \\
\hline \multicolumn{2}{|l|}{ Unit cell dimensions } \\
\hline$a(\AA)$ & 7.0791(10) \\
\hline$b(\AA)$ & $8.5514(13)$ \\
\hline$c(\AA)$ & $8.9031(13)$ \\
\hline$\alpha\left({ }^{\circ}\right)$ & $81.237(4)$ \\
\hline$\beta\left(^{\circ}\right)$ & $74.171(4)$ \\
\hline$\gamma\left({ }^{\circ}\right)$ & $65.686(4)$ \\
\hline Volume $\left(\AA^{3}\right)$ & 376.52 \\
\hline$Z$ & 1 \\
\hline$D_{\text {calc }}\left(\mathrm{mg} \mathrm{m}^{-3}\right)$ & 2.649 \\
\hline Absorption coefficient $\left(\mathrm{mm}^{-1}\right)$ & 1.753 \\
\hline$F(000)$ & 372 \\
\hline Crystal colour & Green \\
\hline Range of $\theta$ for data collection $\left({ }^{\circ}\right)$ & $2.38-26.38$ \\
\hline \multicolumn{2}{|l|}{ Data collection } \\
\hline Reflections collected & 4952 \\
\hline Independent reflections & 1700 \\
\hline Reflections with $I>2 \sigma(I)$ & 1405 \\
\hline Limiting indices & $h=-8 \rightarrow 8, k=-10 \rightarrow 10, l=-11 \rightarrow 11$ \\
\hline \multicolumn{2}{|l|}{ Refinement } \\
\hline Refinement method & Full-matrix least squares on $F^{2}$ \\
\hline$R\left[F^{2}>2 \sigma\left(F^{2}\right)\right]$ & 0.04 \\
\hline $\mathrm{wR}\left(F^{2}\right)$ & 0.10 \\
\hline
\end{tabular}


Table 2. Atomic coordinates and equivalent thermal agitation $U_{\text {eq }}\left(\AA^{2}\right)$ and isotropic $U_{\text {iso }}$ $\left(\AA^{2}\right)$ in $\left[\mathrm{C}_{6} \mathrm{H}_{6} \mathrm{NO}_{2}\right]_{2} \mathrm{CuCl}_{4} \cdot \mathrm{H}_{2} \mathrm{O}$.

\begin{tabular}{lcccl}
\hline Atoms & $x$ & $y$ & $z$ & $U_{\text {iso }} / U_{\text {eq }}$ \\
\hline O1 & $0.1738(2)$ & $0.5386(4)$ & $0.3481(4)$ & $0.0822(18)$ \\
O2 & $0.3824(2)$ & $0.2750(2)$ & $0.4141(4)$ & $0.0828(14)$ \\
N & -0.1325 & $0.1851(4)$ & $0.1981(4)$ & $0.0441(5)$ \\
C1 & $0.0124(3)$ & $0.0774(2)$ & $0.2739(4)$ & $0.0460(14)$ \\
C2 & $0.1322(3)$ & $0.1366(2)$ & $0.3279(4)$ & $0.0434(5)$ \\
C3 & $0.1014(3)$ & $0.3079(4)$ & $0.3025(4)$ & $0.0371(5)$ \\
C4 & -0.0520 & $0.4161(4)$ & $0.2241(4)$ & $0.0448(13)$ \\
C5 & -0.1669 & $0.3505(2)$ & $0.1714(2)$ & $0.0468(14)$ \\
C6 & $0.2329(4)$ & $0.3749(3)$ & $0.3611(2)$ & $0.0498(14)$ \\
Cu & 0.50000 & 0.00000 & 0.00000 & $0.0356(7)$ \\
C11 & $0.73046(12)$ & -0.11489 & $0.15775(13)$ & $0.0538(4)$ \\
C12 & $0.54081(12)$ & $0.25272(5)$ & -0.01993 & $0.0500(4)$ \\
O3 & $0.6047(2)$ & $0.2982(4)$ & $0.6046(4)$ & $0.0593(5)$ \\
H & -0.20722 & 0.14598 & 0.16494 & 0.0530 \\
H1 & 0.03201 & -0.03779 & 0.28996 & 0.0548 \\
H2 & 0.23367 & 0.06235 & 0.38143 & 0.0523 \\
H4 & -0.07653 & 0.53219 & 0.20746 & 0.0538 \\
H5 & -0.26900 & 0.42134 & 0.11702 & 0.0562 \\
H11 & 0.25210 & 0.56609 & 0.38181 & 0.1231 \\
H13 & $0.549(9)$ & $0.283(4)$ & $0.689(3)$ & $0.09(7)$ \\
H23 & 0.50814 & 0.31021 & 0.55914 & 0.0709 \\
\hline
\end{tabular}

$U_{\text {iso }}$ is the isotropic thermal agitation.

Table 3. Factors of anisotropic thermal agitation for $\left[\mathrm{C}_{6} \mathrm{H}_{6} \mathrm{NO}_{2}\right]_{2} \mathrm{CuCl}_{4} \cdot \mathrm{H}_{2} \mathrm{O}$.

\begin{tabular}{lllllll}
\hline Atoms & \multicolumn{1}{c}{$U$} & \multicolumn{1}{c}{$U 22$} & \multicolumn{1}{c}{$U 33$} & $U 12$ & $U 13$ & $U 23$ \\
\hline $\mathrm{O} 2$ & $0.059(7)$ & $0.107(28)$ & $0.090(7)$ & -0.037 & -0.039 & -0.015 \\
$\mathrm{~N}$ & $0.039(7)$ & $0.0461(15)$ & $0.0533(13)$ & -0.0105 & -0.0139 & -0.0179 \\
$\mathrm{C} 1$ & $0.048(28)$ & $0.0360(13)$ & $0.053(7)$ & $0.0002(12)$ & -0.0106 & -0.017 \\
$\mathrm{C} 2$ & $0.038(7)$ & $0.0392(13)$ & $0.048(7)$ & $0.0001(18)$ & -0.0136 & -0.0085 \\
$\mathrm{C} 3$ & $0.031(7)$ & $0.0393(13)$ & $0.0399(13)$ & -0.0110 & -0.0034 & -0.0124 \\
$\mathrm{C} 4$ & $0.042(28)$ & $0.0305(15)$ & $0.060(7)$ & -0.0026 & -0.0165 & -0.0091 \\
$\mathrm{C} 5$ & $0.042(28)$ & $0.040(7)$ & $0.058(7)$ & $0.0008(12)$ & -0.0238 & -0.009 \\
$\mathrm{C} 6$ & $0.036(28)$ & $0.057(7)$ & $0.057(7)$ & -0.018 & -0.0083 & -0.015 \\
$\mathrm{Cu}$ & $0.0377(4)$ & $0.0304(28)$ & $0.0396(28)$ & $0.0014(7)$ & -0.0110 & -0.0139 \\
$\mathrm{Cl} 1$ & $0.0610(4)$ & $0.0371(2)$ & $0.0779(4)$ & $0.0123(2)$ & -0.0413 & -0.0228 \\
$\mathrm{Cl} 2$ & $0.0704(8)$ & $0.0372(2)$ & $0.0580(3)$ & $0.0097(4)$ & -0.0339 & -0.0283 \\
$\mathrm{O} 3$ & $0.069(7)$ & $0.072(7)$ & $0.0528(13)$ & $0.0101(18)$ & -0.0233 & -0.0416 \\
\hline
\end{tabular}

touch, both will display a red spot identical in colour intensity as well as size and shape. The $d_{\text {norm }}$ values are mapped onto the Hirshfeld surface using a red-blue-white colour scheme: red regions correspond to closer contacts and negative $d_{\text {norm }}$ value, the blue regions correspond to longer contacts and positive $d_{\text {norm }}$ value and the white regions are those where the distance of contacts is exactly the vdW separation and with a $d_{\text {norm }}$ value of zero. The combination of $d_{\mathrm{e}}$ and $d_{\mathrm{i}}$ in the form of a 2D fingerprint plot provides summary of intermolecular contacts in the crystal.

\subsection{Spectroscopic measurements}

The vibrational measurements were carried out at room temperature. The infrared spectrum was taken on a 'Nicole
Impact 410 FT-IR' spectrophotometer in the region 400$4000 \mathrm{~cm}^{-1}$. The sample for this measurement was finely ground and mixed with $\mathrm{KBr}$. This mixture was then pressed under vacuum at high pressure to obtain a transparent disc, which was then placed in the sample compartment. The Raman spectrum of polycrystalline sample was performed in the 50-4000 $\mathrm{cm}^{-1}$ range employing a LABRAMHR 800 triple monochromatic instrument using the $514.5 \mathrm{~nm}$ line spectra-physics argon ion lasers.

\subsection{Computational details}

The density functional theory (DFT) approaches, especially those using hybrid functionals, have evolved to a powerful and very reliable tool, being commonly used for the 
determination of various properties of molecules. Within the framework of the DFT approach, the B3LYP hybrid functional has often been preferred since it proved efficient in reproducing various molecular properties. The combined use of B3LYP functional with the LanL2DZ basis set has previously been shown to provide an excellent compromise between accuracy and computational efficiency of vibrational spectra for large and medium size molecules.

The geometry and frequencies were fully optimized at the density functional level of theory with the Becke 3 parameter hybrid functional combined with the Lee-Yang-Parr correlation functional (B3LYP), implemented with Gaussian 03 program [16]. LanL2DZ was used as the basis set. The atomic coordinates for calculations were obtained from the $\mathrm{X}$-ray data. First, the geometry optimization was performed using DFT with the B3LYP correlation functional. It is to be noted that LanL2DZ was used as the basis for all atoms. Therefore, the calculations converged to optimized geometries that corresponded to true energy minima, as revealed by the lack of imaginary values in the vibrational mode calculations. Besides, the vibrational frequencies calculations were performed at the DFT/LanL2Dz level.

The calculated geometrical parameters of the title compound are reported and compared to the experimental ones in table 4.

\section{Results and discussion}

\subsection{Structure description}

The (4-aminopyridinium) tetrachlorocuprate (II) monohydrate compound crystallizes in the triclinic system $P \overline{1}$ at room temperature with the following parameters: $a=7.0791(10) \AA$, $b=8.5514(13) \AA, c=8.9031(13) \AA, \alpha=81.237(4)^{\circ}, \beta=$ $74.171(4)^{\circ}, \gamma=65.686(4)^{\circ}$ and $Z=1$. The formula unit of the title compound (shown in figure 1a), drawn with 50\% probability thermal ellipsoids shows the presence of one anionic entity $\left[\mathrm{CuCl}_{4}\right]^{2-}$, one molecule of water and one cation $\left[\mathrm{C}_{6} \mathrm{H}_{6} \mathrm{NO}_{2}\right]^{2+}$.

The examination of the structure has clearly shown an alternation of organic-inorganic layers that run parallel to the $a$ axis. The first layer is composed of isolated square planar $\left[\mathrm{CuCl}_{4}\right]^{2-}$ and the second layer of $\left[\mathrm{C}_{6} \mathrm{H}_{6} \mathrm{NO}_{2}\right]^{2+}$. The water molecules are sandwiched between the $\left[\mathrm{CuCl}_{4}\right]^{2-}$ anion and the $\left[\mathrm{C}_{6} \mathrm{H}_{6} \mathrm{NO}_{2}\right]^{2+}$ cation on both sides of the layer (figure 2).

Inorganic layers are extended as zero-dimensional (0D) network by isolated square planar $\left[\mathrm{CuCl}_{4}\right]^{2-}$ (figure 3), forming chains running along the axis $b$. The $\left[\mathrm{CuCl}_{4}\right]^{2-}$ anions are located in the [110] plane at $x=1 / 2$. The copper (II) ion is coordinated by four chlorine atoms, with $\mathrm{Cu}-\mathrm{Cl}$ distances ranging from 2.2601(14) to 2.2703(12) $\AA$ and $\mathrm{Cl}-\mathrm{Cu}-\mathrm{Cl}$ angles varying from $90.50(4)$ to $390.50(4)^{\circ}$. The distortion of the $\left[\mathrm{CuCl}_{4}\right]^{2-}$ square planar is correlated to the deformations resulting from hydrogen bond interactions $[17,18]$. The two negative charges of the anionic species are contra-balanced by the two positive charges of the organic cation.

The organic part consists of one organic cation type, which orients its nitrogen towards the neighbouring anion. Table 4 reports the main geometrical features of $\left[\mathrm{C}_{6} \mathrm{H}_{6} \mathrm{NO}_{2}\right]^{2+}$ entities. The $\mathrm{C}-\mathrm{C}$ bond lengths vary from $1.364(4)$ to $1.502(8)$ $\AA$; the $\mathrm{C}-\mathrm{O}$ bond lengths vary from $1.283(3)$ to $1.211(4) \AA$ and the mean value of the $\mathrm{N}-\mathrm{C}$ bond lengths is $1.325(3) \AA$.

The compound has an extensive network of hydrogen bonding due to numerous acceptor and donor atoms. In the crystal structure the 4-cyanopyridine cations are linked to $\left[\mathrm{CuCl}_{4}\right]^{2-}$ by $\mathrm{C}-\mathrm{H} . . . \mathrm{Cl}$ and $\mathrm{N}-\mathrm{H} . . . \mathrm{Cl}$ hydrogen bond, forming infinite chains. At the same time the components of the structure are linked to molecule of water in

Table 4. Comparison between experimental and theoretical interatomic parameters of $\left[\mathrm{C}_{6} \mathrm{H}_{6} \mathrm{NO}_{2}\right]_{2} \mathrm{CuCl}_{4} \cdot \mathrm{H}_{2} \mathrm{O}$.

\begin{tabular}{|c|c|c|c|c|c|}
\hline Bond length $(\AA)$ & Experimental & Theoretical & Bond angle $\left({ }^{\circ}\right)$ & Experimental & Theoretical \\
\hline \multicolumn{6}{|l|}{$\left[\mathrm{CuCl}_{4}\right]^{2-}$} \\
\hline $\mathrm{Cu}-\mathrm{Cl1}$ & $2.2603(12)$ & 2.285 & $\mathrm{Cl} 1-\mathrm{Cu}-\mathrm{Cl} 2$ & $90.51(4)$ & 90.66 \\
\hline $\mathrm{Cu}-\mathrm{Cl} 2$ & $2.2704(10)$ & 2.259 & $\mathrm{Cl1}-\mathrm{Cu}-\mathrm{Cl1}$ & 180.00 & 179.37 \\
\hline $\mathrm{Cu}-\mathrm{Cl1}$ & $2.2603(12)$ & 2.271 & $\mathrm{Cl} 1-\mathrm{Cu}-\mathrm{Cl} 2$ & $89.49(4)$ & 89.82 \\
\hline $\mathrm{Cu}-\mathrm{Cl} 2$ & $2.2704(10)$ & 2.249 & $\mathrm{Cl} 2-\mathrm{Cu}-\mathrm{Cl} 2$ & 180.00 & 178.61 \\
\hline \multicolumn{6}{|l|}{$\left[\mathrm{C}_{6} \mathrm{H}_{6} \mathrm{NO}_{2}\right]^{2+}$} \\
\hline $\mathrm{O} 1-\mathrm{C} 14$ & $1.283(3)$ & 1.297 & $\mathrm{C} 1-\mathrm{N}-\mathrm{C} 5$ & $122.8(4)$ & 123.76 \\
\hline $\mathrm{O} 2-\mathrm{C} 14$ & $1.211(4)$ & 1.238 & $\mathrm{~N}-\mathrm{C} 1-\mathrm{C} 2$ & $119.86(4)$ & 119.32 \\
\hline $\mathrm{N} 2-\mathrm{C} 1$ & $1.325(3)$ & 1.34 & $\mathrm{C} 1-\mathrm{C} 2-\mathrm{C} 3$ & $119.4(4)$ & 118.74 \\
\hline $\mathrm{N} 2-\mathrm{C} 3$ & $1.325(2)$ & 1.34 & $\mathrm{C} 2-\mathrm{C} 3-\mathrm{C} 4$ & 119.2(4) & 119.17 \\
\hline $\mathrm{C} 1-\mathrm{C} 6$ & $1.364(4)$ & 1.384 & $\mathrm{C} 2-\mathrm{C} 3-\mathrm{C} 6$ & $120.8(28)$ & 120.16 \\
\hline $\mathrm{C} 3-\mathrm{C} 4$ & $1.365(4)$ & 1.381 & C4-C3-C6 & $120.8(4)$ & 121.82 \\
\hline $\mathrm{C} 4-\mathrm{C} 5$ & $1.387(3)$ & 1.408 & $\mathrm{C} 3-\mathrm{C} 4-\mathrm{C} 5$ & $119.2(28)$ & 118.01 \\
\hline C5-C14 & $1.502(8)$ & 1.512 & $\mathrm{~N}-\mathrm{C} 5-\mathrm{C} 4$ & $119.7(4)$ & 118.82 \\
\hline \multirow[t]{3}{*}{ C5-C6 } & $1.384(3)$ & 1.394 & $\mathrm{O} 2-\mathrm{C} 6-\mathrm{C} 3$ & $119.8(4)$ & 121.27 \\
\hline & & & $\mathrm{O} 1-\mathrm{C} 6-\mathrm{O} 2$ & $125.6(2)$ & 124.62 \\
\hline & & & $\mathrm{O} 1-\mathrm{C} 6-\mathrm{C} 3$ & 114.6(4) & 112.10 \\
\hline
\end{tabular}




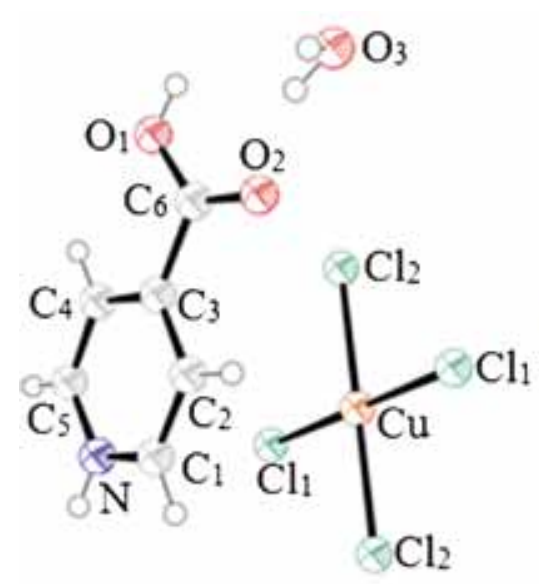

(a)

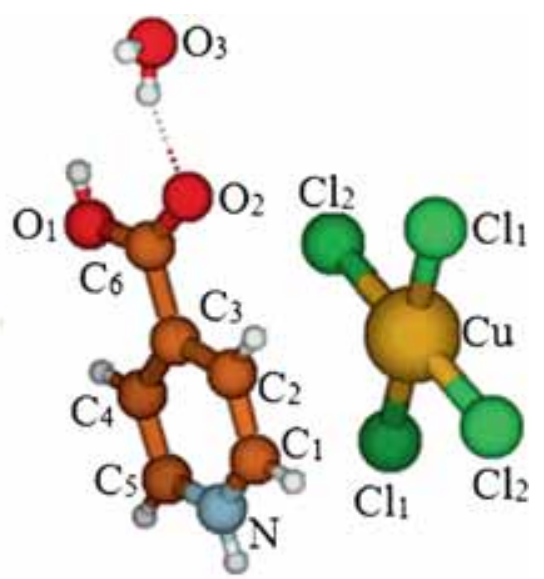

(b)

Figure 1. Atom numbering scheme of the title compound: (a) experimental results and (b) optimized geometry.

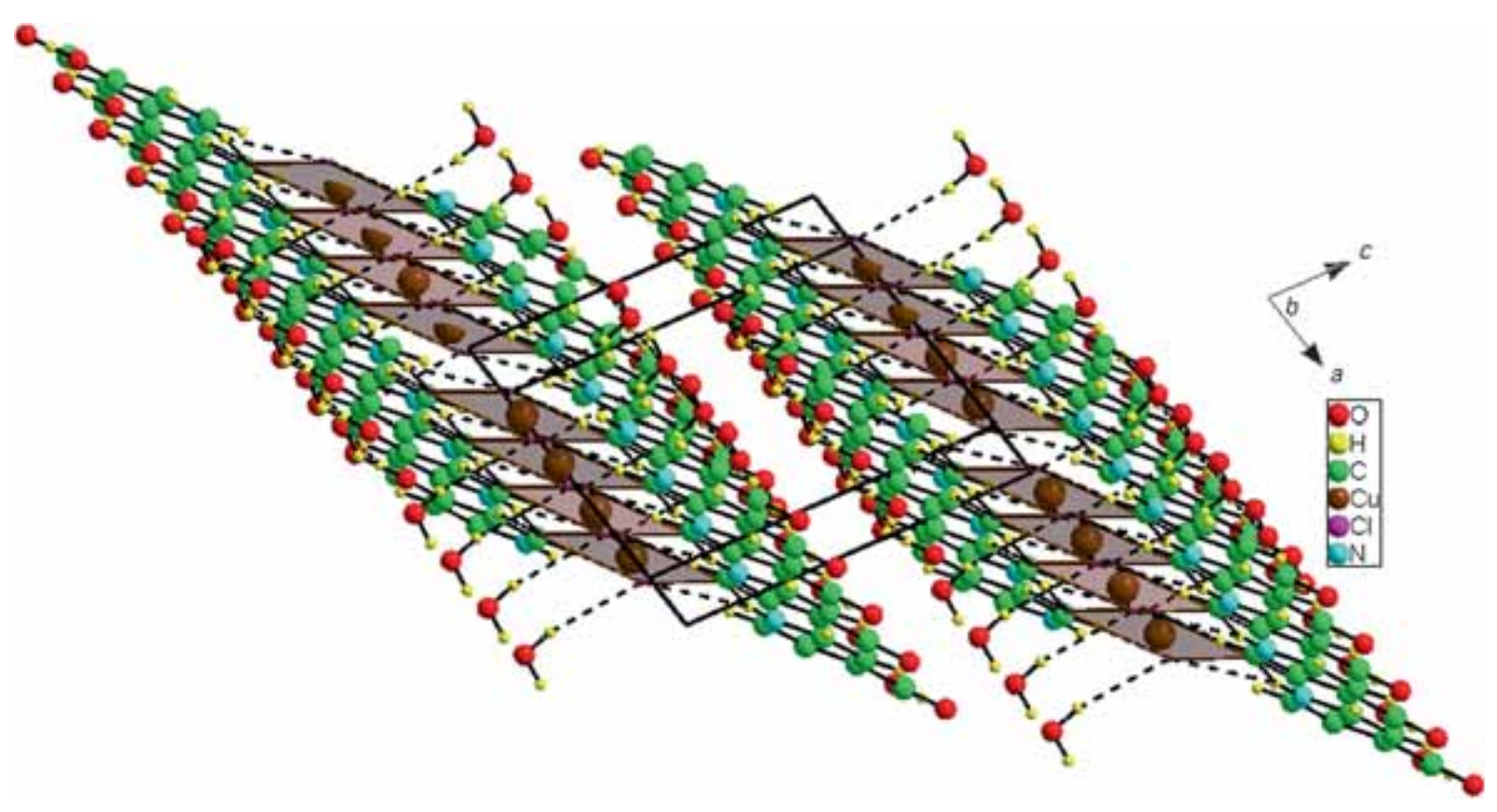

Figure 2. Packing diagram showing the alternation between different entities in $\left[\mathrm{C}_{6} \mathrm{H}_{6} \mathrm{NO}_{2}\right] \mathrm{CuCl}_{4} \cdot \mathrm{H}_{2} \mathrm{O}$.

the crystallographic $c$ direction by $\mathrm{O}-\mathrm{H} . . . \mathrm{O}$ and $\mathrm{O}-\mathrm{H} . . . \mathrm{Cl}$ hydrogen bond to form a second set of infinite chains (figure $4 \mathrm{a}$ ). In addition to these hydrogen interactions, we also note that the cohesion in the crystal is ensured by weak interactions type $\pi-\pi$ stacking observed between the planes containing the fused aromatic rings. The interstacking distances are equal to $3.210 \AA$, which is comparable to interplanar distances found in the aromatic $\pi$-system (figure $4 b$ ) [19].

Both hydrogen bond and $\pi-\pi$ stacking interactions cause the formation of a three-dimensional architecture.

According to the charge compensation hypothesis, the observed structure of copper (II) halides salts can be visualized as a balance between crystal field stabilization effects and an electrostatic ligand-ligand repulsion effect. In fourcoordinate compounds, the former favours a square-planar and the latter a tetrahedral geometry. As long as hydrogen bonds tend to remove charge from the $\mathrm{Cl}$ atoms they will promote the $\left[\mathrm{CuCl}_{4}\right]^{2-}$ ion to move towards a square-planar geometry.

DFT is developing rapidly as a cost-effective general procedure for studying vibrational properties of molecules. Optimized geometry of the title compound model is presented in figure $1 \mathrm{~b}$. Selected measured bond lengths and bond angles together with the calculated ones are presented in table 4 in accordance with the atom numbering scheme given in figure 1a. After careful comparison, we find that most of the optimized bond lengths are slightly larger than 

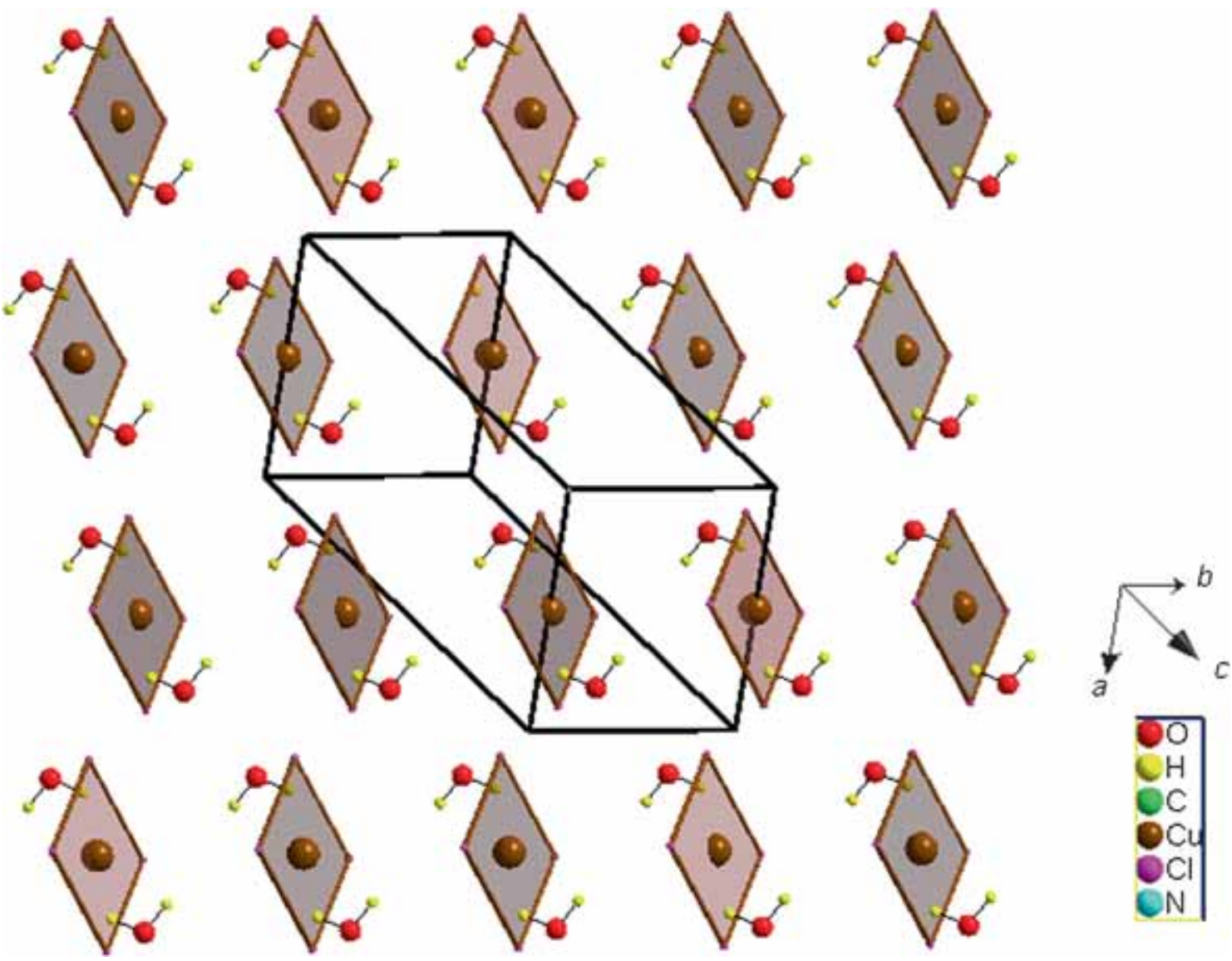

Figure 3. Drawing showing the arrangement of the square plane $\left[\mathrm{CuCl}_{4}\right]^{2-}$.

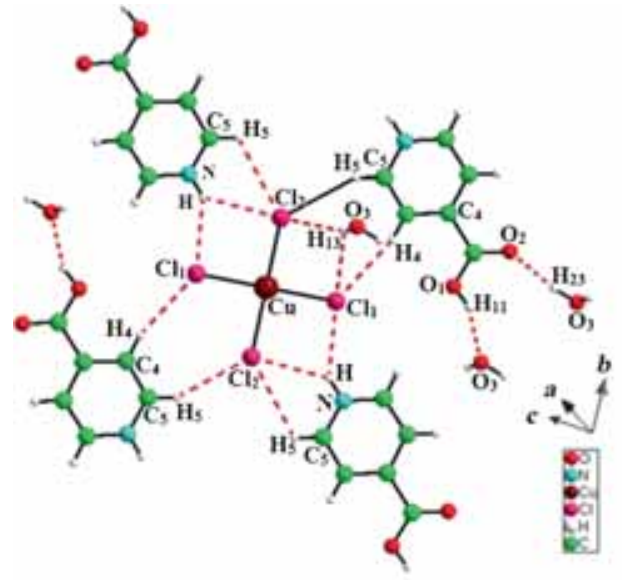

(a)

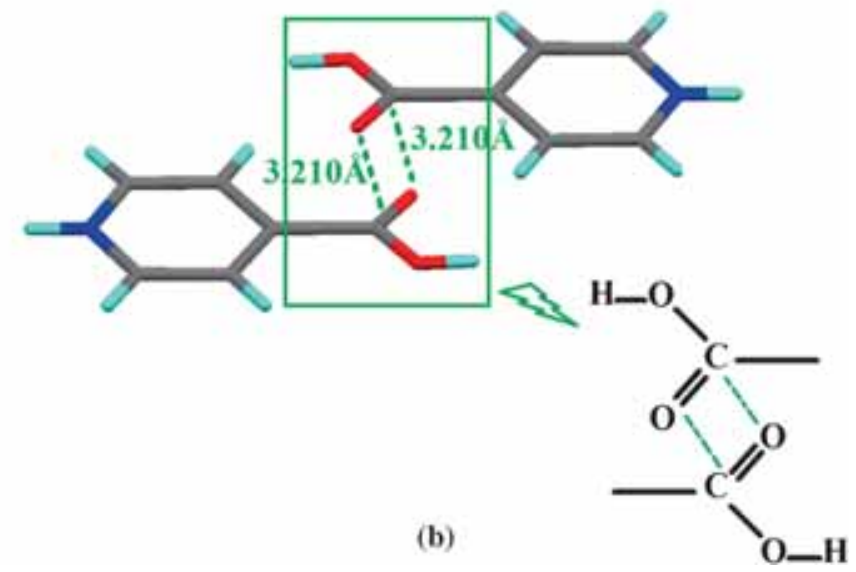

(b)

Figure 4. Packing diagram showing the two interactions between different entities in $\left[\mathrm{C}_{6} \mathrm{H}_{6} \mathrm{NO}_{2}\right] \mathrm{CuCl}_{4} \cdot \mathrm{H}_{2} \mathrm{O}$. (a) Hydrogen bonds among $\left[\mathrm{CuCl}_{4}\right]^{2-}$ anion, $\mathrm{H}_{2} \mathrm{O}$ and $\left[\mathrm{C}_{6} \mathrm{H}_{6} \mathrm{NO}_{2}\right]^{2+}$ cation and $(\mathbf{b}) \pi-\pi$ interaction between the chains of aromatic ring.

the experimental values, which is not surprising given that theoretical calculation belongs to the isolated molecule in the gaseous phase at $0 \mathrm{~K}$ and the experimental result belongs to the molecule in the solid state with intermolecular interactions and crystal packing effect. As shown in table 4, the optimized parameters are in good agreement with the experimental data. 


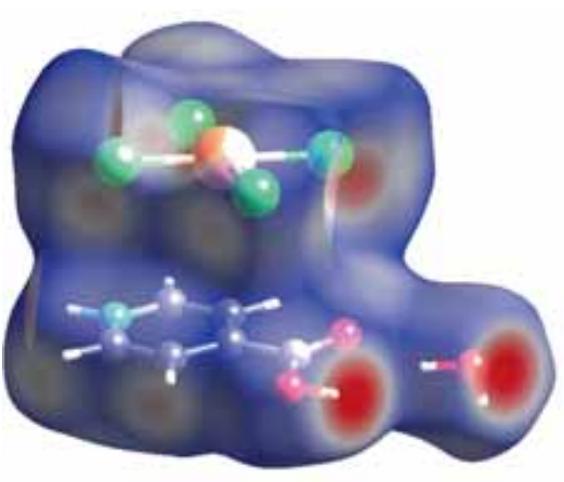

(a)

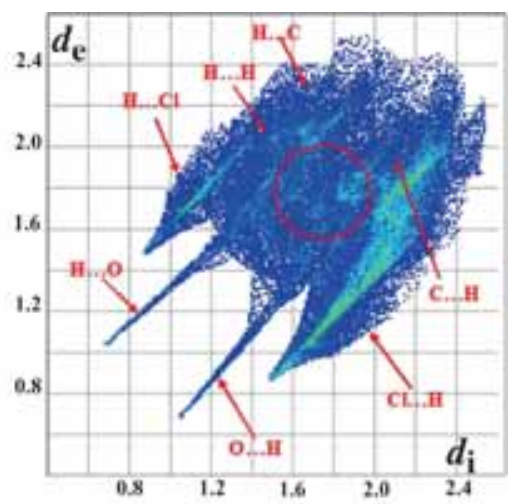

(b)

Figure 5. (a) Hirshfeld $d_{\text {norm }}$ surfaces and (b) full fingerprint for $\left[\mathrm{C}_{6} \mathrm{H}_{6} \mathrm{NO}_{2}\right]$ $\mathrm{CuCl}_{4} \cdot \mathrm{H}_{2} \mathrm{O}$.

Table 5. Hydrogen bonds for $\left[\mathrm{C}_{6} \mathrm{H}_{6} \mathrm{NO}_{2}\right]_{2} \mathrm{CuCl}_{4} \cdot \mathrm{H}_{2} \mathrm{O}$.

\begin{tabular}{lcccc}
\hline D-H ... A & D-H $(\AA)$ & H . . A $(\AA)$ & D . . A $(\AA)$ & D-H ... A $(\AA)$ \\
\hline N-H . . Cl1 & 0.8600 & 2.4600 & $3.189(4)$ & 143.00 \\
N-H . Cl2 & 0.8600 & 2.5500 & $3.234(4)$ & 137.00 \\
O1-H11 . . O3 & 0.8200 & 1.8600 & $2.632(2)$ & 156.00 \\
O3-H13 . . Cl2 & $0.77(2)$ & $2.55(2)$ & $3.233(4)$ & $149(4)$ \\
O3-H23 . . O2 & 0.8500 & 1.8800 & $2.685(2)$ & 159.00 \\
C4-H4 . . Cl1 & 0.9300 & 2.7700 & $3.673(28)$ & 163.00 \\
C5-H5 . . Cl2 & 0.9300 & 2.8200 & $3.674(4)$ & 153.00 \\
\hline
\end{tabular}

Symmetry codes: $-x, 1-y,-z$.

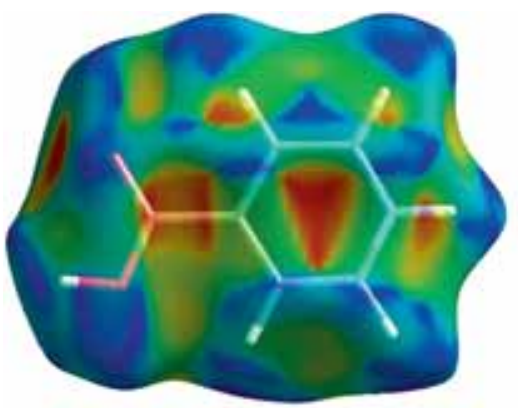

Shape index

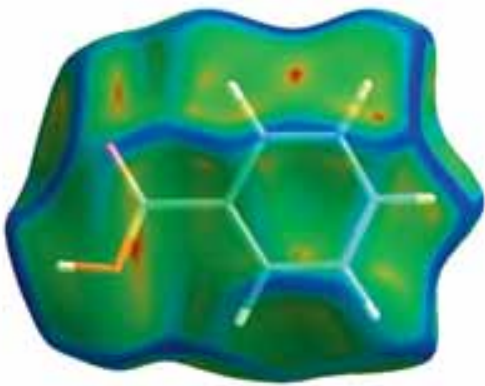

Curvature

Figure 6. Hirshfeld surfaces mapped for shape index and curvature of $\left[\mathrm{C}_{6} \mathrm{H}_{6} \mathrm{NO}_{2}\right]$ $\mathrm{CuCl}_{4} \cdot \mathrm{H}_{2} \mathrm{O}$.

The difference between the calculated and experimental bond lengths and bond angles of the title compound is very small. This indicates that the calculation precision is satisfactory and the DFT/B3LYP/LanL2DZ level is suitable for the complex system studied here.

\subsection{Hirshfeld surface analysis}

In order to profoundly examine the strength and role of the hydrogen bonds and other intermolecular contacts, and to estimate their importance for the crystal lattice stability, Hirshfeld surface analysis has been conducted. The Hirshfeld surface of the title compound is illustrated in figure 5a, showing surfaces that have been mapped over a $d_{\text {norm }}$ range of -0.5 to $1.5 \AA$. The surfaces are shown as transparent to allow visualization of the molecular moiety, in a similar orientation for all of the structures. It is clear that the information presented in table 5 is summarized effectively in these spots, with the large circular depressions (deep red) visible on the surfaces indicative of hydrogen-bonding contacts.

The 2D fingerprint plots, which are used to analyse all of the intermolecular contacts at the same time, revealed that the main intermolecular interactions in the compound were $\mathrm{H} . . . \mathrm{Cl}, \mathrm{H} . . . \mathrm{O}$ and $\mathrm{H} . . . \mathrm{H}$ (figure $5 \mathrm{~b}$ ).

The Hirshfeld surfaces of (4-aminopyridinium) tetrachlorocuprate (II) monohydrate are illustrated in figure 6, 
showing surfaces that have been mapped for shape index and curvature.

Curvature conveys similar information as that of shape index. In fact, the $\pi-\pi$ stacking is shown by the pattern of red and blue triangles on the same region of the shape index surfaces. It is shown by the large flat region delineated by a blue outline on the curvature surfaces.

In order to find out directional interactions, the characteristic features in the fingerprint plots obtained from the Hirshfeld surface were further analysed. This analysis shows the relative contribution of each contact present in the title compound (figure 7). As previously observed, the highest contribution occurs due to $\mathrm{Cl}$...H and $\mathrm{H}$... Cl contacts $(46 \%)$. The O...H interactions are represented by a spike in the bottom left (donor) area of the fingerprint plot, which represents the water oxygen interacting with acid oxygen, forming a 2D network of hydrogen bonds. The H...O interactions are represented by a spike in the bottom right region of fingerprint plot (acceptor). The proportion of H...H interactions comprises $18.6 \%$ of the total Hirshfeld surfaces. Lower percentages
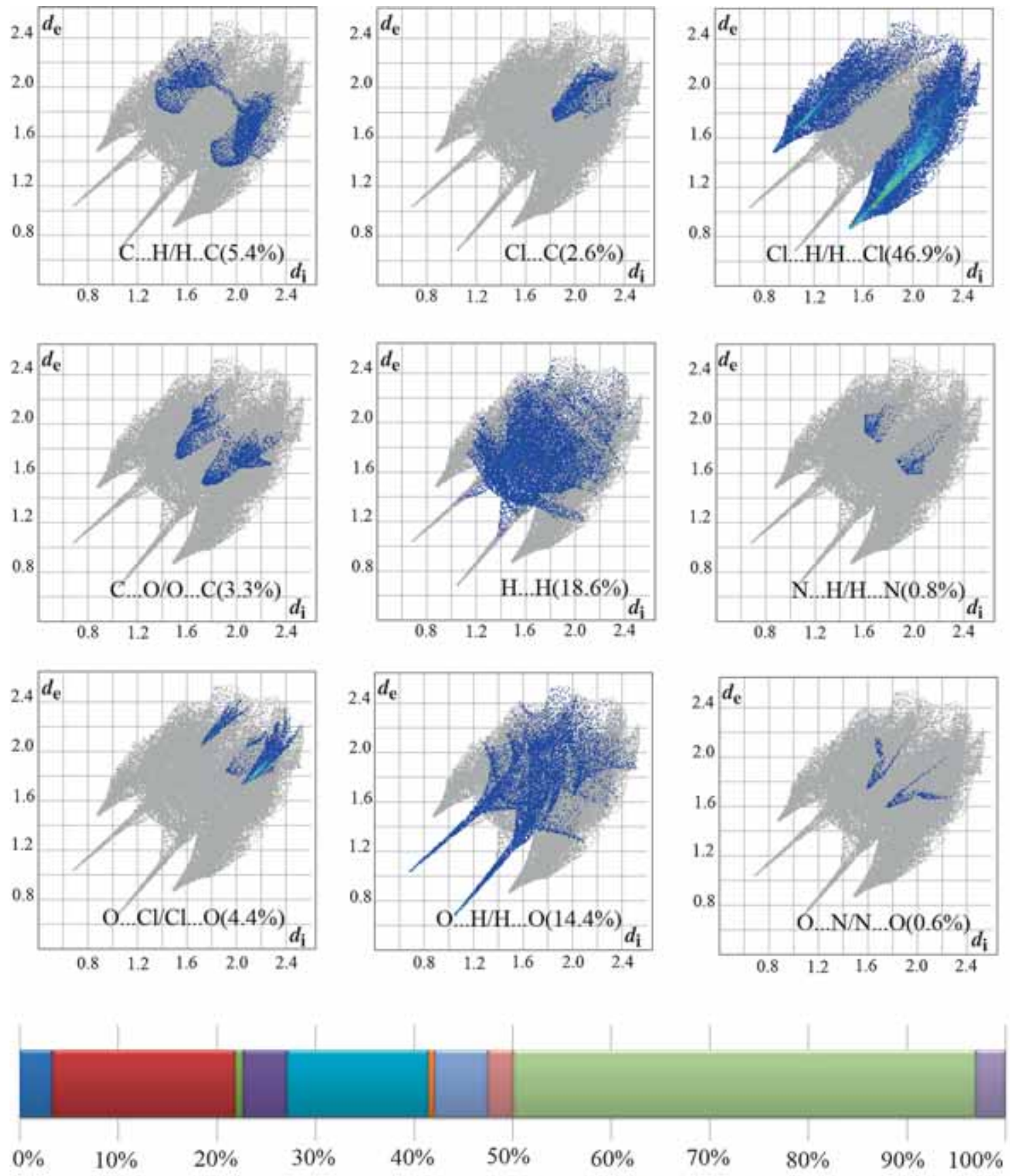

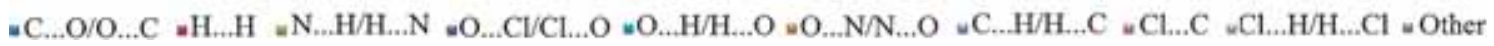

Figure 7. Relative contributions to the percentage of Hirshfeld surface area for the various intermolecular contacts in the title compounds. 
are observed for the $\mathrm{C} . . \mathrm{H} / \mathrm{H} . . . \mathrm{C}(5.4 \%)$ and $\mathrm{O} . . . \mathrm{Cl} / \mathrm{Cl}$... $(4.4 \%)$ contacts, with the last contact contribution corresponding largely to other interactions. The relative contribution of the different interactions to the Hirshfeld surface is presented in figure 7 ; the $\mathrm{Cl}$...H/H...Cl interactions have the most participations in crystal structures.

\subsection{Vibrational studies}

To gain more information on the crystal structure, we have undertaken a vibrational study using infrared spectroscopy and Raman scattering. The FT-infrared and the FT-Raman spectra of the title compound are shown in figures 8 and 9,

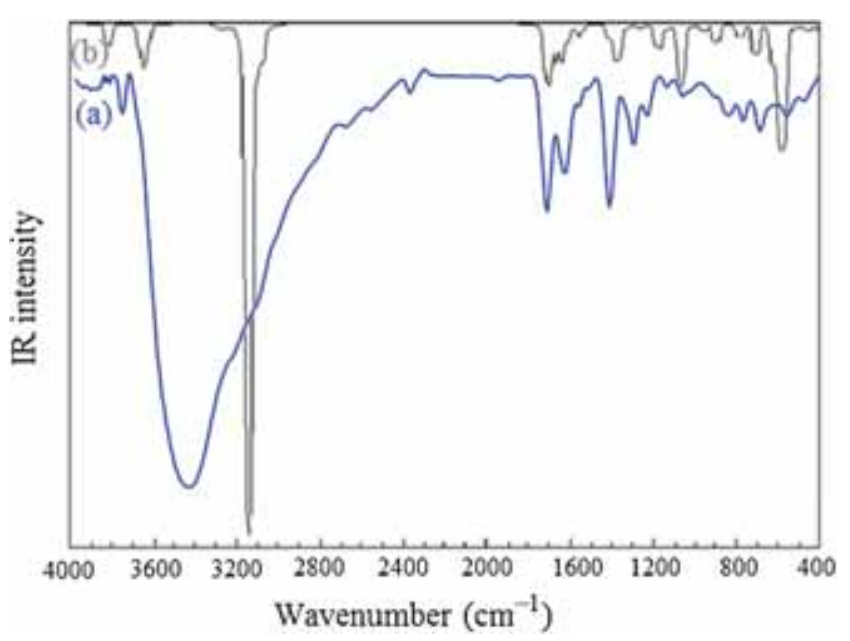

Figure 8. (a) Experimental and (b) simulated FT-IR spectra of the title compound in the region $400-4000 \mathrm{~cm}^{-1}$ recorded at room temperature.

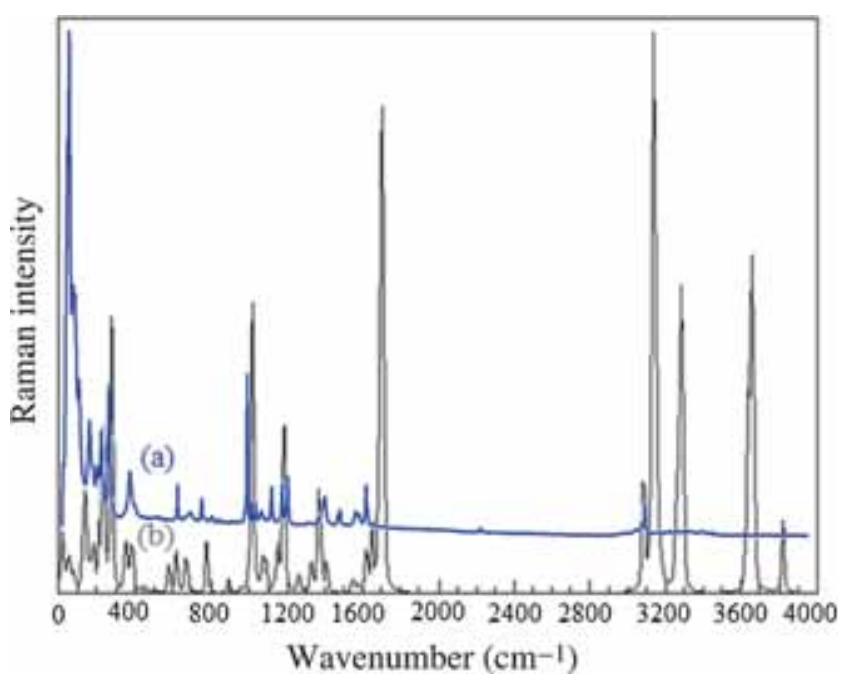

Figure 9. (a) Experimental and (b) simulated FT-Raman spectra of the title compound in the region $50-4000 \mathrm{~cm}^{-1}$ recorded at room temperature. respectively. Although a detailed assignment of all the bands is difficult, the most important attribution mode is realized by comparison with similar compounds [20,21]. The observed and computed wavenumbers and detailed assignments are summarized in table 6 .

3.3a $\left[\mathrm{CuCl}_{4}\right]$ anion mode: The bands observed at 92 and $84 \mathrm{~cm}^{-1}$ are assigned to $\mathrm{Cl}-\mathrm{Cu}-\mathrm{Cl}$ bending and the DFT calculations give this mode at 107 and $84 \mathrm{~cm}^{-1}$. The $\mathrm{Cl}-\mathrm{Cu}-\mathrm{Cl}$ deformation mode is found at 145 and $116 \mathrm{~cm}^{-1}$ and it is predicted at 154 and $130 \mathrm{~cm}^{-1}$ according to DFT/B3LYP/LanL2DZ calculations. The observed large bands at 296 and $255 \mathrm{~cm}^{-1}$ are assigned to the asymmetric and symmetric $\mathrm{Cl}-\mathrm{Cu}-\mathrm{Cl}$ stretching, respectively, and are predicted at 322 and $261 \mathrm{~cm}^{-1}$ according to DFT/B3LYP/LanL2DZ calculations. It is obvious that the agreement between the observed and calculated frequencies is reasonable, showing that the DFT/B3LYP/LanL2DZ performed for the system presented in figure $1 \mathrm{~b}$ has accurately modelled the system.

3.3b $\left[\mathrm{H}_{2} \mathrm{O}\right]$ molecule mode: When the water molecule is in isolated state, it has the $\mathrm{C} 2 \mathrm{v}$ symmetry and $3 N-6$ internal vibrations are presented where $N=3$ is the number of atoms. The $\mathrm{H}_{2} \mathrm{O}$ deformation mode is observed at $1595 \mathrm{~cm}^{-1}$. This value will shift towards higher ones if at least one of the $\mathrm{H}$ atoms is involved in a hydrogen bond.

The bands, observed at $3450 \mathrm{~cm}^{-1}$ and calculated at $3525 \mathrm{~cm}^{-1}$ in FT-IR, are ascribed to stretching vibration of $\mathrm{O}-\mathrm{H}$. The asymmetric and symmetric stretching vibrations of $\mathrm{H}_{2} \mathrm{O}$ group are not observed in the FT-IR and FT-Raman spectra but predicted at 3675 and $3502 \mathrm{~cm}^{-1}$ according to DFT/B3LYP/LanL2DZ calculations, respectively.

3.3c $\left[\mathrm{C}_{6} \mathrm{H}_{6} \mathrm{NO}_{2}\right]$ cation mode: In our present work, the $\mathrm{C}-\mathrm{H}$ stretching vibrations are observed at $3113 \mathrm{~cm}^{-1}$ as weak bands in Raman spectrum. The $\mathrm{C}-\mathrm{H}$ ring stretching modes are found to be weak, which is due to the charge transfer between the hydrogen atoms and carbon atoms. The scaled vibrations by the B3LYP/LanL2DZ method predicted at $3163 \mathrm{~cm}^{-1}$ show good agreement with recorded spectral data.

The weak bands at $1710 \mathrm{~cm}^{-1}$ in the infrared are assigned to the $\mathrm{COOH}$ bending modes. The corresponding vibrations in the FT-Raman spectrum appear at $1730 \mathrm{~cm}^{-1}$. As seen from table 6 , the calculated $\mathrm{COOH}$ vibration wavenumbers show good agreement with experimental data. Besides, the band located at 1620 and $1600 \mathrm{~cm}^{-1}$ in the FT-IR and FTRaman spectra, respectively, corresponds to the $\mathrm{CH}$ rocking; the corresponding calculated value is $1624 \mathrm{~cm}^{-1}$.

The $\mathrm{O}-\mathrm{H}$ stretching mode is located experimentally at $1060 \mathrm{~cm}^{-1}$ in infrared spectrum, at $1065 \mathrm{~cm}^{-1}$ in FT-Raman spectrum and predicted theoretically at $1069 \mathrm{~cm}^{-1}$. Concerning the wavenumbers found between 770 and $782 \mathrm{~cm}^{-1}$ in FT-IR and FT-Raman spectra, they are attributed to $\mathrm{C}-\mathrm{N}-\mathrm{C}$ 
Table 6. Wavenumbers $\left(\mathrm{cm}^{-1}\right)$ and relative assignments of the observed and calculated bands in the FT-infrared and FT-Raman spectrum of $\left[\mathrm{C}_{6} \mathrm{H}_{6} \mathrm{NO}_{2}\right]_{2} \mathrm{CuCl}_{4} \cdot \mathrm{H}_{2} \mathrm{O}$.

\begin{tabular}{|c|c|c|c|}
\hline \multicolumn{2}{|c|}{ Observed wavenumbers $\left(\mathrm{cm}^{-1}\right)$} & \multirow{2}{*}{$\begin{array}{l}\text { Wavenumbers calculated by } \\
\text { B3LYP/LanL2DZ }\left(\mathrm{cm}^{-1}\right)\end{array}$} & \multirow[b]{2}{*}{ Assignments } \\
\hline FT-IR & Raman & & \\
\hline - & - & 3675 & $\mathrm{H}_{2} \mathrm{O}$ asymmetric stretching \\
\hline 3450 & - & 3525 & $\mathrm{O}-\mathrm{H}$ bending \\
\hline- & - & 3502 & $\mathrm{H}_{2} \mathrm{O}$ symmetric stretching \\
\hline - & 3113 & 3163 & $\mathrm{~N}-\mathrm{H}$ stretching \\
\hline 1710 & 1730 & 1707 & $\mathrm{COOH}$ stretching \\
\hline 1620 & 1600 & 1624 & $\mathrm{C}-\mathrm{H}$ rocking \\
\hline - & 1507 & 1516 & $\mathrm{H}_{2} \mathrm{O}$ deformation \\
\hline - & 1435 & 1460 & $\mathrm{C}-\mathrm{C}-\mathrm{C}$ scissoring \\
\hline 1410 & - & 1407 & $\mathrm{C}-\mathrm{H}$ rocking and $\mathrm{N}-\mathrm{H}$ in-plane bending \\
\hline 1290 & - & 1317 & $\mathrm{C}-\mathrm{O}-\mathrm{H}$ deformation \\
\hline 1230 & 1237 & 1260 & $\mathrm{C}-\mathrm{C}-\mathrm{H}$ deformation \\
\hline- & 1155 & 1183 & $\mathrm{C}-\mathrm{N}-\mathrm{C}$ deformation \\
\hline 1060 & 1065 & 1069 & O-H stretching \\
\hline- & 1019 & 1020 & $\mathrm{C}-\mathrm{C}-\mathrm{C}$ deformation \\
\hline 840 & 838 & 85 & $\mathrm{C}-\mathrm{H}$ out-of-plane bending \\
\hline 770 & 782 & 77 & $\mathrm{C}-\mathrm{N}-\mathrm{C}$ and $\mathrm{C}-\mathrm{C}-\mathrm{C}$ deformation \\
\hline 680 & 650 & 68 & C-H out-of-plane bending \\
\hline 550 & - & 57 & $\mathrm{H}_{2} \mathrm{O}$ wagging \\
\hline 460 & - & 49 & COO rocking \\
\hline- & 405 & 42 & Ring deformation \\
\hline - & 296 & 32 & $\mathrm{Cl}-\mathrm{Cu}-\mathrm{Cl}$ asymmetric stretching \\
\hline - & 265 & 28 & $\mathrm{H}_{2} \mathrm{O}$ twisting \\
\hline - & 255 & 26 & $\mathrm{Cl}-\mathrm{Cu}-\mathrm{Cl}$ symmetric stretching \\
\hline - & 190 & 22 & $\mathrm{H}_{2} \mathrm{O}$ scissoring \\
\hline - & $145-116$ & $15-13$ & $\mathrm{Cl}-\mathrm{Cu}-\mathrm{Cl}$ deformation \\
\hline - & $92-84$ & $10-84$ & $\mathrm{Cl}-\mathrm{Cu}-\mathrm{Cl}$ bending \\
\hline
\end{tabular}

deformation. Our DFT calculations give these modes at $777 \mathrm{~cm}^{-1}$.

The bands in FT-IR spectrum and in FT-Raman spectrum, located at 680 and $650 \mathrm{~cm}^{-1}$, respectively, are assigned to the mode stretching of $\mathrm{C}-\mathrm{H}$. The computed wavenumber is $680 \mathrm{~cm}^{-1}$.

Finally, as table 6 shows, the experimental wavenumbers of the title compound are found to compare well with the data obtained by DFT/B3LYP/LanL2DZ method.

\section{Conclusion}

In summary, a novel organic-inorganic hybrid compound, $\left[\mathrm{C}_{6} \mathrm{H}_{6} \mathrm{NO}_{2}\right] \mathrm{CuCl}_{4} \cdot \mathrm{H}_{2} \mathrm{O}$, has been successfully synthesized at room temperature by slow evaporation. The structure consists of alternation of organic and inorganic layers. Hirshfeld surfaces display all of the intermolecular interactions within the crystal at once and are therefore ideal for analysing the crystal packing. The vibrational properties of this structure were studied by FT-infrared spectroscopy and FT-Raman scattering. The assignment of the vibrational bands was based on comparisons with vibrational mode frequencies of homologous compounds and theoretical vibrational mode calculated by DFT/B3LYP/LanL2DZ.

\section{Acknowledgements}

We would like to thank the members of units of common services, in particular Mr Tarek Gargouri, at the University of Sfax for their assistance in the measurements of X-ray diffraction. We are also thankful to Prof Hamadi Khemakhem for co-operating in the Raman spectroscopy measurement.

\section{Electronic Supplementary Material}

Crystallographic data for the title compound, have been deposited at the Cambridge Crystallographic Data Centre as supplementary publication CCDC 1046854. Copies of these data can be obtained, free of charge, on application to CCDC, 12 Union Road, Cambridge CB21EZ, UK (fax: +44(0)-1223-336033 or e-mail: deposit@ccdc.cam.ac.uk).

\section{References}

[1] Hajlaoui S, Chaabane I, Oueslati A, Guidara K and Bulou A 2014 Spectrochim. Acta A 117225

[2] Chaabane I, Hlel F and Guidara K 2008 J. Alloys Compd. 461 495 
[3] Ben Bechir M, Karoui K, Tabellout M, Guidara K and Ben Rhaiem A 2014 J. Alloys Compd. 588551

[4] Karâa N, Hamdi B, Salah A and Zouari R 2012 J. Mol. Struct. 1013168

[5] Willett R D and Twamley B 2001 Acta Crystallogr. 57 573

[6] Kurawa M A, Adams C J and Orpen A G 2008 Acta Crystallogr. E 64924

[7] Swamy G Y S K, Ravikumar K and Ramakrishna K V S 2013 Polyhedron 49145

[8] Bhattacharya R, Ray M S, Dey R, Righi L, Bocelli G and Ghosh A 2002 Polyhedron 212561

[9] Farrugia L J 1999 J. Appl. Crystallogr. 32837

[10] Sheldrick G M 1986 SHELXS-86 program for crystal structure solution (Germany: University of Gottingen)

[11] Sheldrick G M 1997 SHELXL-97 program for crystal structure refinement (Germany: University of Gottingen)

[12] Farrugia L J 1997 J. Appl. Crystallogr. 30565
[13] Brandenburg K 1998 Diamond Version 2.0 (Bonn, Germany: Impact GbR)

[14] Wolff S K, Grimwood D J, McKinnon J J, Turner M J, Jayatilaka D and Spackman M A 2013 Crystal Explorer Version 3.1 (Perth: University of Western Australia)

[15] Seth S K, Saha N C, Ghosh S and Kar T 2011 Chem. Phys. Lett. 506309

[16] Frisch M J, Trucks G W, Schlegel H B, Scuseria G E, Robb M A, Cheeseman J R et al 2004 Gaussian 03, Revision C 02 (Wallingford: Gaussian Inc)

[17] Zhu R Q 2011 Acta Crystallogr. E 67112

[18] Elangovan A, Thamaraichelvan A, Ramu A, Athimoolame S and Natarajan S Acta Crystallogr. E 63224

[19] Karâa N, Hamdi B, Oueslati A, Salah A and Zouari R 2010 J. Inorg. Organomet. Polym. 20746

[20] Hajlaoui S, Chaabane I, Oueslati A, Guidara K and Bulou A. 2014 Spectrochim. Acta A 117225

[21] Chen R H, Chen Y C, Shern C S and Fukami T 2009 J. Solid State Ion. 180356 